\title{
High-resolution anoscopy, is there a benefit in proceeding directly to the operating room?
}

\author{
B. Moeckli ${ }^{1,2}$ - J. Canner ${ }^{1} \cdot$ A. Najafian ${ }^{3} \cdot$ S. Carbunaru ${ }^{4} \cdot$ N. Cowell ${ }^{1} \cdot$ C. Atallah $^{1} \cdot$ E. Paredes ${ }^{1} \cdot$ A. Chudnovets $^{1}$. \\ S. H. Fang ${ }^{1}$
}

Received: 21 September 2020 / Accepted: 22 January 2021 / Published online: 10 February 2021

(c) The Author(s) 2021

\begin{abstract}
Background The development of high-resolution anoscopy (HRA) has advanced our ability to detect anal dysplasia. Historically, HRA is performed in a clinical setting and subsequent ablation is performed in the clinical setting or operating room. The aim of this study was to determine the most effective venue for the performance of HRA.

Methods Following institutional review board (IRB) approval, the correlation between anal cytology and HRA performed in the clinic versus in the operating room was evaluated. Data were extracted from our IRB-approved prospective HRA database over the time period of 2013-2017.

Results One hundred twenty-eight HRAs were compared (101 in the clinical setting, 27 in the operating room). There was a statistically significant difference in the correlation between anal cytology and HRA pathology for procedures performed in the clinical setting (55\% [56/101]) versus those performed in the operating room (82\% [22/27]) $(p=0.014)$. More biopsies were obtained in the operating room than in the clinic setting ( 3 vs. $1, p<0.0001$ ). The majority of patients who had HRA in a clinical setting with subsequent HRA in the operating room stated that they preferred to have their HRAs performed in the operating room due to discomfort from the HRA procedure.

Conclusions Detection rates for anal dysplasia on HRA, are significantly higher when performed in the operating room. To prevent discomfort in the clinical setting, patients with high-grade dysplasia on anal pap testing may benefit from proceeding directly to the operating room for concurrent HRA and ablation.
\end{abstract}

Keywords High-resolution anoscopy $\cdot$ Anal cancer $\cdot$ High-grade dysplasia $\cdot$ Anal pap smear $\cdot$ Patient comfort

\section{Introduction}

$\triangle$ S. H. Fang

sfang7@jhmi.edu

1 Department of Surgery, Ravitch Division of Colon and Rectal Surgery, High Resolution Anoscopy Clinic, The Johns Hopkins Hospital, Johns Hopkins University School of Medicine, 600 N. Wolfe St., Blalock 618, Baltimore, MD 21287, USA

2 Department of Surgery, Geneva University Hospitals, Geneva, Switzerland

3 Department of Plastic Surgery, Oregon Health Sciences University, Portland, OR, USA

4 Northwestern University School of Medicine, Chicago, IL, USA
Each year 8200 new cases of anal cancer are responsible for close to 1100 deaths in the United States [1]. Although anal squamous neoplasms only represent a small proportion of the total number of cancer cases of digestive tract neoplasms, its incidence has risen over the past few decades while survival has not improved [2, 3]. In addition, certain subgroups of patients, which include human immunodeficiency virus (HIV)-positive men who have sex with men (MSM), have a significantly increased risk of developing anal cancer. The yearly incidence of anal cancer for HIVpositive MSM in the United Stated is reported to be 137 per 100,000 compared to 1.5 per 100,000 for the general population [4], a rate that exceeds the incidence of cervical cancer prior to the introduction of a widespread screening program in England [5]. 
A number of similarities exist between cervical cancer and anal squamous cell carcinoma (ASCC). Both occur at a squamocolumnar junction, a transitional zone characterized by high cell turnover, and are associated with high-risk human papillomavirus (HPV) infection [6]. Furthermore, both exhibit a stepwise progression from precancerous lesions to invasive carcinoma [7]. HPV-associated progression ranges from normal squamous cell epithelium to lowgrade squamous intraepithelial lesions (LSIL) to high-grade squamous intraepithelial lesions (HSIL), and ultimately to invasive cancer $[8,9]$, with a median transformation time from high-grade dysplasia to invasive neoplasia ranging from 14 to 120 months $[10,11]$. Patients with early anal cancer have an excellent 5 -year survival rate of $>80 \%$. Whereas those with advanced disease with distant metastasis have a 5 -year survival rate of 30\% [12].This highlights the importance of early detection.

One of the major public heath success stories of the past century has been the widespread introduction of cytology based Papanicolaou (Pap) test to detect pre-neoplastic lesions in cervical cancer, resulting in a drastic reduction in mortality [13]. Analogously anal cancer lends itself to a targeted screening program. This is due to a clearly defined high-risk group, combined with a long latent phase and markedly improved survival for early versus late stage disease. Professional society guidelines from the American Society of Colon and Rectal Surgeons (ASCRS) recommend screening of high-risk individuals with anal Pap tests [2]. Suspicious lesions from the anal Pap test are further characterized with high-resolution anoscopy (HRA).

Historically, HRA is performed in a clinical setting whereas subsequent ablation is accomplished either in a clinic-based setting or in the operating room (OR). However, to our knowledge there are no objective data, which indicate which setting is best for performing HRA. The aim of this study was to determine the best setting for the performance of HRA.

\section{Materials and methods}

\section{Study design}

Data were obtained from our prospectively maintained institutional review board (IRB)-approved HRA database. All patients, aged 18 years and older who had HRA with biopsy, between November 1, 2011 and July 30, 2017, were reviewed from our IRB-approved prospective HRA database. Patients who did not provide written informed consent to be a part of the HRA database, had HRA without biopsies, or did not have biopsy results available, were excluded. Repeat HRAs were also excluded to avoid confounding since HRAs in the OR were more frequently repeat procedures.

\section{Anal cytology and HRA}

Anal Pap tests and HRAs were performed in our weekly HRA clinic. Patients were referred to the clinic from their primary care physicians or our institution's HIV clinic if they had a history of abnormal Pap test results.

In clinic, patients were placed in the left lateral decubitus position with their knees tucked to their chest. For anal cytology, a Dacron swab was inserted into the anus with the tip just proximal to the dentate line. The swab was rotated within the anal canal for at least $30 \mathrm{~s}$, while withdrawing the swab, to obtain a proper anal Pap specimen. A baseline anoscopy was performed to visualize the anal canal. Five-percent acetic acid soaked gauze was placed at the dentate line for 2 min and then removed. Under colposcopic visualization, the dentate line was identified and neovascular acetowhite lesions were identified and biopsied with an endoscopic cold biopsy forceps. Lugol's solution was applied and inspected with the colposcope. Suspicious Lugol's negative lesions were biopsied with an endoscopic cold biopsy forceps. Monsel's solution was applied for hemostasis. Anal cytology and HRA biopsies were reviewed by the Pathology Department at the Johns Hopkins Hospital.

In the operating room, the patient was placed in prone jack-knife position, under either conscious sedation or general anesthesia, with administration of a local perianal field block.

Cytological findings were categorized as no dysplasia, atypical squamous cells of undetermined significance (ASCUS), low-grade dysplasia (LSIL), or high-grade dysplasia (HSIL, low-grade squamous intraepithelial lesions suspicious for HSIL, and atypical squamous cells suspicious for HSIL).

Histopathological results from the anal biopsies obtained during the HRA were classified using the most recent two-tiered classification system recommended by the Lower Anogential Squamous Terminology Project [8]. The most severe biopsy result from each patient was used if several biopsies were obtained. Condyloma and Anal Intraepithelial Neoplasia (AIN) - 1 were classified as LSIL, AIN-2 and AIN-3 were categorized as HSIL.

We determined that there was a correlation between the HRA and anal cytology in the following scenarios:

- If anal cytology and the histopathological assessment of the anal biopsy were in the same category according to the two-tiered classification system (HSIL, LSIL or no dysplasia); i.e., HSIL on anal cytology matched HSIL on anal biopsy and so forth.

- If anal cytology was ASCUS and the histopathological assessment of the anal biopsy was HSIL, LSIL, or no dysplasia 
We determined that there was no correlation between HRA and anal cytology in the following scenarios:

- If anal cytology was HSIL but the biopsies obtained during the HRA were low grade or negative

- If anal cytology was LSIL and the biopsies obtained during HRA were HSIL.

\section{Statistical analysis}

Independent t-tests and the Kruskal wallis test were used to compare groups with respect to continuous variables. All variables were presented as medians with interquartile ranges (IQR). Counts and proportions were analyzed using chi-square tests. All statistical analyses were performed using Stata ${ }^{\circledR} /$ MP 14.2 (StataCorp LLC, College Station, TX, USA). A $p$ value of $<0.05$ was considered to be significant.

\section{Results}

Overall 128 patients were included in this retrospective study, of which 27 underwent HRA in in the OR and 101 in a clinic setting. A summary of patient demographic data is presented in Table 1 (Table 1). The proportion of men in the group that underwent HRA in the OR was higher. A higher percentage of patients who had HRA in the OR are current smokers, although this did not reach statistical significance. There was no statistically significant difference in age, body mass index, HIV status, comorbidity, or race between the two study groups. The number of biopsies obtained per procedure was significantly higher in the OR group with a median of 3 (range 2-4) biopsies compared to 1 (range 1-2) biopsy for the clinic group $(p=<0.0001)$. There was a trend toward more post procedural bleeding and pain in the OR group which did not reach statistical significance $(p=0.16$ and $p=0.64$, respectively) (Table 2 ).

We observed an increased correlation between anal cytology and HRA pathology in the OR group that was statistically significant with a concordance of $81 \%$ compared to a correlation of $55 \%$ in the clinic group $(p=0.014)$ (Fig. 1).

\section{Discussion}

HRA is a technique that was first described in 1989 by Scholefield et al. [14] and first performed in the United States by Dr. Michael Berry at University of California-San Francisco. [15]. The benefits of HRA are uncontested and its main utility lies in increased sensitivity and specificity for detecting pre-cancerous lesions compared to cytology-based
Table 1 Demographic and clinical characteristics of patients having high-resolution anoscopy

\begin{tabular}{lllll}
\hline Characteristic & & OR $(n=27)$ & Clinic $(n=101)$ & $p$ value \\
\hline Age (years), median (IQR) & & $47(41-54)$ & $49(39-54)$ & 0.72 \\
Sex: male & & $14(52 \%)$ & $31(31 \%)$ & 0.04 \\
BMI $\left(\mathrm{kg} / \mathrm{m}^{2}\right)$, median (IQR) & & $29.0(22.0-31.5)$ & $26.6(23.6-28.4)$ & 0.08 \\
Race & Asian & $0(0 \%)$ & $2(2 \%)$ & \\
& Caucasian & $12(44 \%)$ & $46(47 \%)$ & \\
& Black & $13(48 \%)$ & $44(45 \%)$ & 0.36 \\
& Hispanic & $1(4 \%)$ & $1(1 \%)$ & \\
HIV + & Other & $0(0 \%)$ & $3(3 \%)$ & \\
CD4 count $<200^{\mathrm{b}}$ & & $18(67 \%)$ & $74(73 \%)$ & 0.50 \\
Sexual preference & & $1(6 \%)$ & $9(12 \%)$ & 0.46 \\
& MSM & $10(37 \%)$ & $38(40 \%)$ & \\
Smoking (current) & Heterosexual & $7(26 \%)$ & $17(18 \%)$ & 0.19 \\
Comorbidities & Unknown $^{c}$ & $9(33 \%)$ & $41(43 \%)$ & \\
& & $20(74 \%)$ & $52(51 \%)$ & 0.09 \\
& Hypertension & $7(26 \%)$ & $22(22 \%)$ & 0.65 \\
& Diabetes & $1(4 \%)$ & $6(6 \%)$ & 0.64 \\
& Renal insufficiency & $2(7 \%)$ & $3(3 \%)$ & 0.29 \\
& Coronary artery disease & $0(0 \%)$ & $4(4 \%)$ & 0.29 \\
& Ulcerative colitis & $1(4 \%)$ & $1(1 \%)$ & 0.51 \\
\hline
\end{tabular}

$B M I$ body mass index, $M S M$ men who have sex with men, $H I V$ human immunodeficiency virus

${ }^{a}$ Data are presented as number (percentage) unless otherwise noted

${ }^{\mathrm{b}}$ The CD4 count was only available for 91 of the patients and the $p$ value was calculated based on the available data

${ }^{\mathrm{c}}$ Includes missing data and data of patients who declined disclosure of their sexual orientation 
Table 2 Comparison of number of biopsies and complications between HRA performed in the $\mathrm{OR}$ and clinic

\begin{tabular}{lllc}
\hline & OR $(n=27)$ & Clinic $(n=101)$ & $p$ value \\
\hline Number of biopsies, median (IQR) & $3(2-4)$ & $1(1-2)$ & $<0.0001$ \\
Post procedural bleeding $n(\%)$ & $1(4)$ & $1(1)$ & 0.16 \\
Post procedural pain $n(\%)$ & $5(19)$ & $6(6)$ & 0.64 \\
\hline
\end{tabular}

$H R A$ high-resolution anoscopy, $O R$ operating room

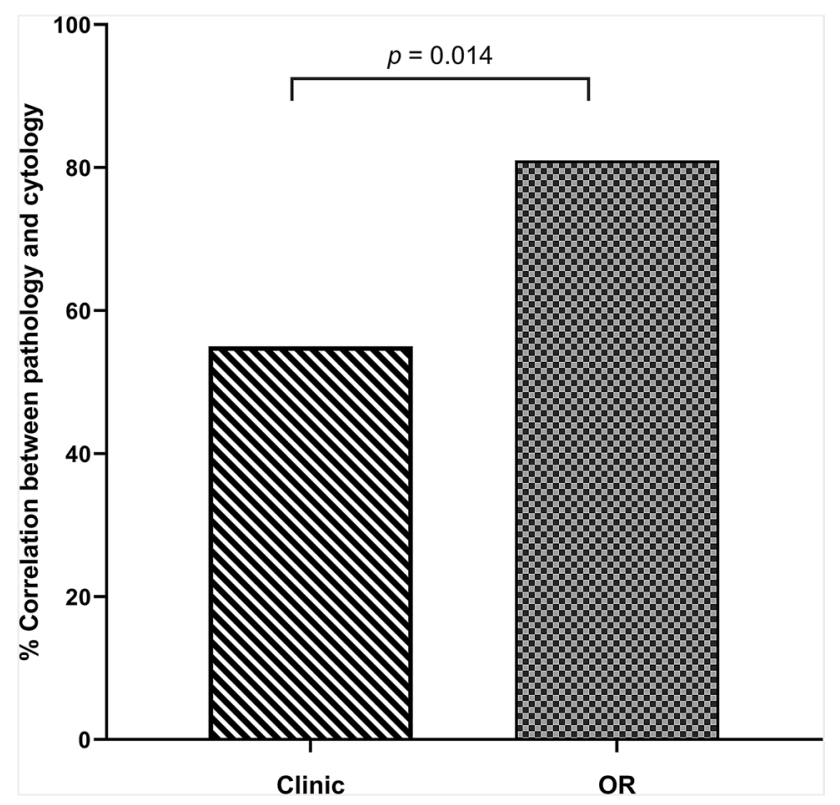

Fig. 1 Correlation between pathology and cytology from high-resolution anoscopy performed in clinic compared to the operating room. $O R$ Operating room, Pearson $\chi^{2}(1)=6.0670, p$ value $=0.014$

methods $[16,17]$. This is further underlined by a Canadian study that identified the use of HRA as the most cost-effective screening strategy relative to other screening modalities including anal Pap tests for the detection of high-grade anal intraepithelial neoplasia [18]. Yet anal cytology and HRA can be used as complementary tests. A finding of high-grade dysplasia on an anal pap test can be indicative of the presence of high-grade pathology on HRA [16, 19].

HRAs performed in the OR exhibit a significantly increased correlation to anal cytology with an $82 \%$ correlation for procedures performed in the OR versus only $51 \%$ correlation to anal cytology for HRA procedures performed in clinic. This increased correlation suggests a higher quality exam when the procedure is performed in the OR. A high discordance of cytology and histology can indicate that a dysplastic lesion has been missed on HRA. In cervical cancer screening practice, cytology and colposcopic-directed biopsy pathology correlation has been used as a quality measure [20] and prior studies show that the majority of discrepancies between colposcopic-directed biopsy pathology and cytology can be explained by sampling error during colposcopic-directed biopsy [21, 22]. Given the striking similarities between anal and cervical cancer screening, we believe that the same situation holds true for anal cytology and HRA biopsy correlation and that sampling errors could be markedly reduced by performing HRAs in the OR.

A recently published prospective study by Roberts et al., shows a clear improvement of the positive predictive value (PPV) of detecting histological HSIL on HRA when the baseline cytology is HSIL over a 12-month period, increasing from 72 to $93 \%$. This finding suggests that foci of HSIL are missed on the baseline HRA examination and an examination in the OR can potentially help to reduce the number of HRA procedures necessary to accurately diagnose preneoplastic lesions.

There are several reasons why performing HRA in the OR may increase detection rate of anal dysplasia. In the OR, patients are subjected to anesthesia and the surgeon is able to place larger anal retractors for better visualization of abnormal lesions. In addition, the anorectal examination is not rushed due to patient discomfort. The patient is placed in prone jack-knife position so that anorectal anatomy is better visualized.

One factor that may have contributed to the higher correlation of anal cytology and HRA pathology is the significantly higher number of biopsies obtained in the OR versus that obtained in clinic. With a median number of three biopsies in the OR, as opposed to one, when performed in clinic, the probability of picking up a dysplastic lesion increases. This is supported by the work of Silvera et al., [23] which showed that taking random biopsies of normal appearing quadrants increased the number of diagnoses of HSIL identified per patient. However, this study reported only an increase of patients with HSIL detected of $9.8 \%$ and therefore would not account for the entirety of the effect that we observed in this study.

Although there are currently no randomized controlled trials looking at the effectiveness of treatment of HSIL several retrospective studies have shown that treatment of high-grade anal dysplasia is both effective in preventing anal cancer and cost effective [24-26].

Previously we performed all screening HRA in our outpatient clinic. After the analysis and comparison of the results between HRAs obtained in the OR and in the outpatient clinic we have revised our patient pathways. We currently perform a concurrent anal Pap test and HRA in clinic. If 
the anal pap test results in high-grade pathology (HSIL), our protocol is to proceed directly to the operating room for HRA with biopsy and ablation, due to our findings that visualization of high-grade lesions in the operating room is superior to visualization in a clinic setting. In addition, if there is any concern about having an awake procedure in clinic or the patient is uncomfortable during the initial examination, then the surgeon will offer to complete the HRA in the operating room. This strategy has several advantages it eliminates the need for an additional procedure and avoids the discomfort associated with an office based HRA. This strategy may also increase patient's compliance to followup. Of the seven procedures that were aborted in our cohort, all of them were performed in the outpatient clinic and five out of seven of the cases were terminated due to patient discomfort.

The limitations of our study also deserve discussion. Our sample size was relatively low. In addition, there is the issue of biased patient selection; that is, patients that were seen in HRA clinic had already been pre-screened as "high-risk" because the majority were referred by our institution's HIV care center. As such, our findings are not applicable to large populations, but should be considered a preliminary description of risk that could potentially be applied in appropriate settings such as HIV clinics. Finally, while patients were more comfortable and there was better visualization of the anal canal when the HRA was performed in the operating room, the patients were subjected to the risks of anesthesia.

\section{Conclusions}

Our results suggest that proceeding directly to the OR for HRA in the appropriately selected, high-risk patients with HSIL on anal Pap test is beneficial. It could result in a higher detection rate of dysplastic lesions, increase patient comfort during the procedure and ablation, and decrease the number of unnecessary procedures.

Funding Open Access funding provided by Université de Genève.

\section{Compliance with ethical standards}

Conflict of interest The authors declare that they have no conflict of interest.

Ethical approval This prospectively maintained database was approved by our institutional review board. All procedures performed (high resolution anoscopy and biopsies) were in accordance with the ethical standards of the institutional research committee and with the 1964 Helsinki declaration and its later amendments or comparable ethical standards.
Informed consent For this type of study, formal consent is not required.

Open Access This article is licensed under a Creative Commons Attribution 4.0 International License, which permits use, sharing, adaptation, distribution and reproduction in any medium or format, as long as you give appropriate credit to the original author(s) and the source, provide a link to the Creative Commons licence, and indicate if changes were made. The images or other third party material in this article are included in the article's Creative Commons licence, unless indicated otherwise in a credit line to the material. If material is not included in the article's Creative Commons licence and your intended use is not permitted by statutory regulation or exceeds the permitted use, you will need to obtain permission directly from the copyright holder. To view a copy of this licence, visit http://creativecommons.org/licenses/by/4.0/.

\section{References}

1. SEER Stat Fact Sheets: Anal Cancer (2018) National Cancer Institute.

2. Steele SR, Varma MG, Melton GB, Ross HM, Rafferty JF, Buie WD, Standards Practice Task Force of the American Society of C, Rectal S (2012) Practice parameters for anal squamous neoplasms. Dis Colon Rectum 55(7):735-749. https://doi. org/10.1097/DCR.0b013e318255815e

3. Brewster DH, Bhatti LA (2006) Increasing incidence of squamous cell carcinoma of the anus in Scotland, 1975-2002. Br J Cancer 95(1):87-90. https://doi.org/10.1038/sj.bjc.6603175

4. D’Souza G, Wiley DJ, Li X, Chmiel JS, Margolick JB, Cranston RD, Jacobson LP (2008) Incidence and epidemiology of anal cancer in the multicenter AIDS cohort study. J Acquir Immun Defic Syndr 48(4):491-499. https://doi.org/10.1097/QAI.0b013 e31817aebfe

5. Foley G, Alston R, Geraci M, Brabin L, Kitchener H, Birch J (2011) Increasing rates of cervical cancer in young women in England: an analysis of national data 1982-2006. Br J Cancer 105(1):177-184. https://doi.org/10.1038/bjc.2011.196

6. Frisch M, Glimelius B, van den Brule AJ, Wohlfahrt J, Meijer CJ, Walboomers JM, Goldman S, Svensson C, Adami HO, Melbye M (1997) Sexually transmitted infection as a cause of anal cancer. N Engl J Med 337(19):1350-1358. https://doi. org/10.1056/NEJM199711063371904

7. Reese PP, Hall IE, Weng FL, Schroppel B, Doshi MD, Hasz RD, Thiessen-Philbrook H, Ficek J, Rao V, Murray P, Lin H, Parikh CR (2016) Associations between deceased-donor urine injury biomarkers and kidney transplant outcomes. J Am Soc Nephrol 27(5):1534-1543. https://doi.org/10.1681/ASN.2015040345

8. Darragh TM, Colgan TJ, Cox JT, Heller DS, Henry MR, Luff RD, McCalmont T, Nayar R, Palefsky JM, Stoler MH, Wilkinson EJ, Zaino RJ, Wilbur DC, Members of LPWG (2012) The lower anogenital squamous terminology standardization project for HPV-associated lesions: background and consensus recommendations from the College of American Pathologists and the American Society for Colposcopy and Cervical Pathology. Arch Pathol Lab Med 136(10):1266-1297. https://doi.org/10.5858/ arpa.LGT200570

9. Kreuter A, Potthoff A, Brockmeyer NH, Gambichler T, Swoboda J, Stucker M, Schmitt M, Pfister H, Wieland U, German Competence Network HA (2010) Anal carcinoma in human immunodeficiency virus-positive men: results of a prospective study from Germany. Br J Dermatol 162(6):1269-1277. https ://doi.org/10.1111/j.1365-2133.2010.09712.x 
10. Scholefield JH, Castle MT, Watson NF (2005) Malignant transformation of high-grade anal intraepithelial neoplasia. Br J Surg 92(9):1133-1136. https://doi.org/10.1002/bjs.4994

11. Watson AJ, Smith BB, Whitehead MR, Sykes PH, Frizelle FA (2006) Malignant progression of anal intra-epithelial neoplasia. ANZ J Surg 76(8):715-717. https://doi.org/10.111 1/j.1445-2197.2006.03837.x

12. SEER Cancer Statistics Review, 1975-2014, National Cancer Institute. Bethesda, MD, https://seer.cancer.gov/csr/1975_2014/, based on November 2016 SEER data submission, posted to the SEER web site, April 2017 (2017) https://seer.cancer.gov/ csr/1975_2014/.

13. Landy R, Pesola F, Castanon A, Sasieni P (2016) Impact of cervical screening on cervical cancer mortality: estimation using stage-specific results from a nested case-control study. Br J Cancer 115(9):1140-1146. https://doi.org/10.1038/bjc.2016.290

14. Scholefield JH, Talbot IC, Whatrup C, Sonnex C, Palmer JG, Mindel A, Northover JMA (1989) Anal and cervical intraepithelial neoplasia: possible parallel. The Lancet 334(8666):765769. https://doi.org/10.1016/s0140-6736(89)90830-1

15. Palefsky JM (2012) Practising high-resolution anoscopy. Sex Health 9(6):580-586. https://doi.org/10.1071/SH12045

16. Dalla Pria A, Alfa-Wali M, Fox P, Holmes P, Weir J, Francis N, Bower M (2014) High-resolution anoscopy screening of HIVpositive MSM: longitudinal results from a pilot study. AIDS 28(6):861-867. https://doi.org/10.1097/QAD.0000000000 000160

17. Schofield AM, Sadler L, Nelson L, Gittins M, Desai M, Sargent A, McMahon RF, Hill J, Crosbie EJ, Patnick J, Kitchener HC (2016) A prospective study of anal cancer screening in HIV-positive and negative MSM. AIDS 30(9):1375-1383. https://doi.org/10.1097/ QAD.0000000000001045

18. Lam JM, Hoch JS, Tinmouth J, Sano M, Raboud J, Salit IE (2011) Cost-effectiveness of screening for anal precancers in HIV-positive men. AIDS 25(5):635-642. https://doi.org/10.1097/ QAD.0b013e3283434594

19. Botes LP, Pett S, Carr A, Marriott D, Cooper DA, Matthews G, Carbone S, Kumaradevan N, McHugh L, Hillman RJ (2013) Anal cytological abnormalities are poor predictors of high-grade intraepithelial neoplasia amongst HIV-positive men who have sex with men. Sex Health 10(1):9-17. https://doi.org/10.1071/SH111 35
20. Crothers BA, Jones BA, Cahill LA, Moriarty AT, Mody DR, Tench WD, Souers RJ (2013) Quality improvement opportunities in gynecologic cytologic-histologic correlations: findings from the College of American Pathologists Gynecologic Cytopathology Quality Consensus Conference working group 4. Arch Pathol Lab Med 137(2):199-213. https://doi.org/10.5858/arpa.2012-0250-OA

21. Tritz DM, Weeks JA, Spires SE, Sattich M, Banks H, Cibull ML, Davey DD (1995) Etiologies for non-correlating cervical cytologies and biopsies. Am J Clin Pathol 103(5):594-597

22. Joste NE, Crum CP, Cibas ES (1995) Cytologic/histologic correlation for quality control in cervicovaginal cytology. Experience with 1,582 paired cases. Am J Clin Pathol 103(1):32-34

23. Silvera R, Gaisa MM, Goldstone SE (2014) Random biopsy during high-resolution anoscopy increases diagnosis of anal highgrade squamous intraepithelial lesions. J Acquir Immune Defic Syndr 65(1):65-71. https://doi.org/10.1097/QAI.0b013e3182 a9b3d3

24. Pineda CE, Berry JM, Jay N, Palefsky JM, Welton ML (2008) High-resolution anoscopy targeted surgical destruction of anal high-grade squamous intraepithelial lesions: a ten-year experience. Dis Colon Rectum 51 (6):829-835 (discussion 835-827). https://doi.org/10.1007/s10350-008-9233-4

25. Marks DK, Goldstone SE (2012) Electrocautery ablation of highgrade anal squamous intraepithelial lesions in HIV-negative and HIV-positive men who have sex with men. J Acquir Immune Defic Syndr 59(3):259-265. https://doi.org/10.1097/QAI.0b013e3182 437469

26. Deshmukh AA, Chiao EY, Cantor SB, Stier EA, Goldstone SE, Nyitray AG, Wilkin T, Wang X, Chhatwal J (2017) Management of precancerous anal intraepithelial lesions in human immunodeficiency virus-positive men who have sex with men: Clinical effectiveness and cost-effectiveness. Cancer 123(23):4709-4719. https://doi.org/10.1002/cncr.31035

Publisher's Note Springer Nature remains neutral with regard to jurisdictional claims in published maps and institutional affiliations. 